the active debate about the future of Canadian health care. Knowing a priori that some people would not like whatever our systematic review would uncover, we used several measures to minimize any possible bias. For example, we established explicit eligibility criteria and blacked out all study results before determining study eligibility, so that we were unable to select or reject an article on the basis of the study results. Therefore, we did not, and indeed could not, select studies to reach a preconceived conclusion.

Using our estimate of the additional costs of care in for-profit institutions and a corporate tax rate of $38.1 \%$, Vincent Richman estimates that for-profit hospitals would have to pay $\$ 1.37$ billion in corporate income taxes. Even if corporations were to actually pay all of this income tax and the money was reinvested into health care, Canadians would still be paying an extra $\$ 2.2$ billion annually for health care.

Richman also states that we ignored the effect of competition in moderating prices. The 3 studies in our meta-analysis that controlled for market competition all demonstrated significantly higher payments for care at private forprofit hospitals. ${ }^{3-5}$ Furthermore, a health care system can have competition without private for-profit hospitals, as is the case in many cities with several private not-for-profit hospitals.

Finally, Richman claims that we ignore case mix because we extrapolated our pooled estimate of a mix of hospital payment ratios to the entire Canadian hospital system. We acknowledge that our \$3.6 billion annual excess expenditure is an estimate that assumes a relatively similar case mix to US hospitals. Even if we assume a lower-acuity case mix among Canadian patients, any realistic assumption would result in the Canadian public having to pay billions of dollars in excess expenditures if we introduce private for-profit hospitals.

Considering this reality and given our previous finding of higher death rates in private for-profit hospitals, ${ }^{6}$ our policy recommendation remains robust (i.e., the evidence strongly supports a policy of not-for-profit health care delivery at the hospital level).

\section{P.J. Devereaux}

Department of Medicine

Greg Stoddart

Department of Clinical Epidemiology and Biostatistics

Deborah J. Cook

Department of Medicine

McMaster University

Hamilton, Ont.

\section{References}

1. Devereaux PJ, Heels-Ansdell D, Lacchetti C, Haines T, Burns KEA, Cook DJ, et al. Payments for care at private for-profit and private not-forprofit hospitals: a systematic review and metaanalysis. CMA7 2004;170(12):1817-24.

2. Unwanted results: the ethics of controversial research [editorial]. CMAf 2003;169(2):93.

3. McCue MJ, Clement JP. Relative performance of for-profit psychiatric hospitals in investorowned systems and nonprofit psychiatric hospitals. Am F Psychiatry 1993;150(1):77-82.

4. Sloan FA, Picone GA, Taylor DH, Chou SY. Hospital ownership and cost and quality of care: Is there a dime's worth of difference? $\mathcal{F}$ Health Econ 2001;20(1):1-21.

5. Keeler EB, Melnick G, Zwanziger J. The changing effects of competition on non-profit and forprofit hospital pricing behavior. 7 Health Econ 1999;18(1):69-86.

6. Devereaux PJ, Choi PT, Lacchetti C, Weaver B, Schünemann HJ, Haines T, et al. A systematic review and meta-analysis of studies comparing mortality rates of private for-profit and private not-for-profit hospitals. CMA7 2002;166(11): $1399-406$

DOI:10.1503/cmaj.1041113

\section{The gender gap in Canadian health care}

K irsteen Burton and Ian Wong, in their article on the physician workforce in Canada, ${ }^{1}$ state that "Compared with men, women work fewer hours per week, see fewer patients (and provide fewer services), [and] are likely to leave the medical profession sooner." Additional detail on these points would be helpful in determining the extent of the problem. Specifically, how many fewer hours are worked by female physicians each week, and how many fewer patients do they see? Also, how many years earlier do female physicians retire? Given that the number of doc- tors in the country is declining, these differences represent a serious issue.

Is it wise for taxpayers to fund training for a large group of future part-time doctors, when there is already a shortage of doctors in the country? In their selection process, do medical schools screen on the basis of applicants' plans to work part-time or full-time? If not, perhaps they should.

\section{Herzog \\ Physician \\ Toronto, Ont.}

\section{Reference}

1. Burton KR, Wong IK. A force to contend with The gender gap closes in Canadian medical schools. CMAf 2004;170(9):1385-6.

DOI:10.1503/cmaj.1040984

\section{[The authors respond:]}

$\mathrm{D}$ ifferences in practice between male and female doctors, as described in our article, ${ }^{1}$ are important to uncover, not only in terms of human resource patterns, but also perhaps in terms of the quality of care provided. The cost-benefit analysis that would be involved in deciding whether governments should fund training for a group of part-time doctors is a complex one, involving many factors in addition to number of hours worked, number of patients seen and number of years in medical service. We have not conducted studies or analyses of these factors, although they are certainly worthy of scientific exploration.

\section{Kirsteen R. Burton}

Department of Public Health Sciences

University of Toronto

Toronto, Ont.

Ian K. Wong

Faculty of Medicine

University of British Columbia

Vancouver, BC

\section{Reference}

1. Burton KR, Wong IK. A force to contend with: The gender gap closes in Canadian medical schools. CMA7 2004;170(9):1385-6.

DOI:10.1503/cmaj.1041295 